\title{
INSIGHTS, TRENDS AND CHALLENGES ASSOCIATED WITH MEASURING COAL RELATIVE PERMEABILITY
}

\author{
Dylan Shaw ${ }^{1}$, Peyman Mostaghimi ${ }^{1}$, Furqan Hussain ${ }^{1}$, Ryan T. Armstrong ${ }^{1}$,* \\ 1The University of New South Wales, Sydney, Australia
}

\begin{abstract}
Due to the poroelasticity of coal, both porosity and permeability change over the life of the field as pore pressure decreases and effective stress increases. The relative permeability also changes as the effective stress regime shifts from one state to another. This paper examines coal relative permeability trends for changes in effective stress. The unsteady-state technique was used to determine experimental relative permeability curves, which were then corrected for capillary-end effect through history matching. A modified Brooks-Corey correlation was sufficient for generating relative permeability curves and was successfully used to history match the laboratory data. Analysis of the corrected curves indicate that as effective stress increases, gas relative permeability increases, irreducible water saturation increases and the relative permeability crosspoint shifts to the right.
\end{abstract}

\section{Introduction}

Coal is considered to be a dual porosity/ permeability system (Shi and Durucan, 2004). The coal matrix has low porosity and permeability but provides the surface area required to store a significant amount of methane gas, which is chemically adsorbed to the coals micro-pores (Wu et al, 2017). Coal fractures are void space and their permeability is high compared to the matrix making them the main pathways for flow in the formation (Seidle et al, 1992). These fractures, known as cleats, can be divided into two sets of distinctly different fracture types identified as face cleats that are parallel to the bedding plane and butt cleats that run orthogonal to the bedding plane (Mostaghimi et al, 2016). When studying coal relative permeability under production conditions, fractures likely dominate the relative permeability behaviour due to their absolute permeability being greater than that of the matrix. Even though flow through fractures is well studied, the poroelasticity and adsorption/ desorption mechanics of coal add complexity when trying to understand relative permeability behaviour. Under increasing effective stress loads not only do the fractures change widths, the matrix itself also deforms ( $\mathrm{Lu}$ et al, 2018; Liang et al, 2017). If methane is introduced into the coal matrix and pore pressure is increased then the matrix will adsorb methane and swell. Conversely, if pore pressure is decreased then the matrix will desorb methane and shrink (Harpalani and Schraufnagel, 1990). It can be seen from these basic statements that coal relative permeability must be characterized for a wide range of effective stress states. Although a few papers have published data showing relative permeability at varying effective stress states there has not been a concerted effort to identify nor validate the observed trends (Zhang et al, 2017; Reznik et al, 1974). Examination of data published by Reznik et al. (1974) and Zhang et al. (2017) helps substantiate the trends identified in our work presented herein. Reznik et al. (1974) performed air-water relative permeability testing on Pittsburgh Coal and showed that increasing the overburden pressure while maintaining constant pore pressure resulted in lower water saturation during imbibition floods. Data published by Zhang et al. (2017) also showed an increase in irreducible water saturation as confining pressure is increased and pore pressure is held constant during unsteadystate drainage testing. This indicates a reduction in fluid mobility with increased effective stress as the capillary pressure required to invade cleats increases as cleats are compressed. These observations have also recently been validated by $\mathrm{Lu}$ et al. (2018) by X-ray computed microtomography imaging of coal at reservoir

* corresponding author: ryan.armstrong@unsw.edu.au

() The Authors, published by EDP Sciences. This is an open access article distributed under the terms of the Creative Commons Attribution License 4.0 (http://creativecommons.org/licenses/by/4.0/). 
conditions. To decouple the effect of coal shrinkage/swelling from other factors that influence coal relative permeability, helium gas can be substituted in place of methane for core flooding experiments. It is known that helium gas does not adsorb to coal and thus, will not cause the matrix to shrink/swell, which influences coal absolute permeability and could also potentially influence relative permeability. This is a common technique for analysing the permeability properties of coals (Niu et al, 2018) and is used in our work to understand how effective stress influences coal relative permeability without the influence of matrix shrinkage. Once decoupled, the main controlling factor influencing relative permeability will likely be the rank of the coal since rank is known to be correlated with fracture network development and matrix compressibility (Mahoney et al, 2015; Guo et al, 2014; Close and Mavor, 1991), which is known to influence coal permeability. Literature data on coal that measures relative permeability at different effective stress states are sparse leading to a lack in understanding of the fundamental trends (Zhang et al, 2015). Several attempts have been made to develop a relative permeability model that can predict coal behaviour for any given effective stress (Zhang et al, 2015), but these models often lack a physical basis. As an example, a recent model proposed introduces four new fitting parameters that have no direct link to experimental physics with one of the parameters described as a polynomial function (Chen et al, 2013). The need for such a complex relative permeability model for coal is questionable and the overabundance of fitting parameters obfuscates the underlying physical processes. In addition, lack of coal relative permeability data is partly due to the difficulty of obtaining and maintaining representative samples and the inability to test with reservoir gas. For commercially viable reservoirs the majority of samples are obtained by vertical coring. During this process the samples are often damaged beyond repair in the zones of highest permeability with only the low permeability zones being collected whole. This means that large scale field characterization can be challenging since the major flow paths of the reservoir cannot be tested. The collected samples are also typically damaged and non-cylindrical with large portions missing and rough surfaces. The brittle nature of coal also requires special handling procedures to protect the collected core once delivered to the laboratory to prevent further damage and ensure that samples are suitable for confinement in a core holder.

\section{Materials and Methods}

The sample used for this study originated from an exploration well drilled in the Gloucester Basin found north of Sydney, Australia. Gloucester Basin coal is described as being of high rank with mean maximum vitrinite reflectance (Rvmax) ranging between 0.85 to 1.5 $\%$ with a vertical coalification gradient of 0.07 Rvmax/100m (Gurba and Weber, 2000) and is considered a high volatile bituminous coal (Siregar et al, 2017).

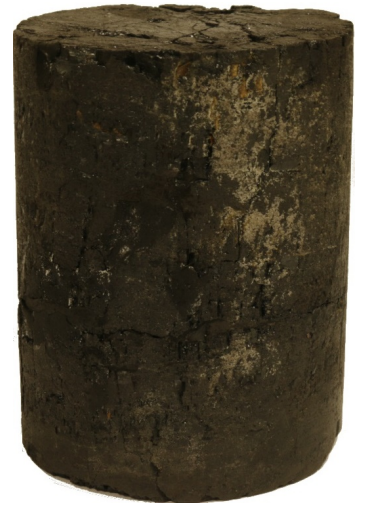

(a)

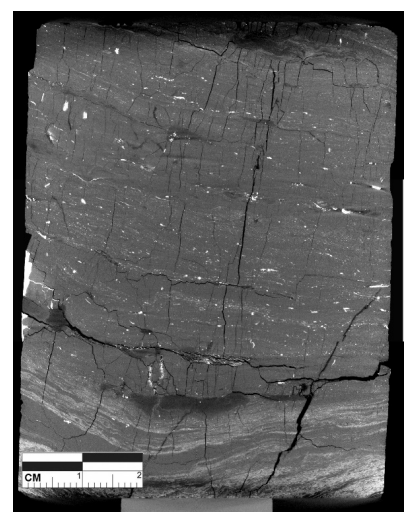

(b)

Figure 1. (a) Is a photograph of sample used in this study (b) On the right is a micro-computed tomography image of the core. 
Table 1. Outline of parameters used for each test

\begin{tabular}{|c|c|c|c|c|c|}
\hline $\begin{array}{c}\text { Test } \\
\text { no. }\end{array}$ & $\begin{array}{c}\text { Confin } \\
\text { ing } \\
(\mathrm{psi})\end{array}$ & $\begin{array}{c}\text { Inlet } \\
(\mathrm{psi})\end{array}$ & $\begin{array}{c}\text { Outl } \\
\text { et } \\
(\mathrm{psi})\end{array}$ & $\begin{array}{c}\text { Pore } \\
\text { Pressure } \\
(\mathrm{psi})\end{array}$ & $\begin{array}{c}\text { Effective } \\
\text { Stress } \\
(\mathrm{psi})\end{array}$ \\
\hline 1 & 800 & 640 & 630 & 165 & 165 \\
\hline 2 & 800 & 315 & 303 & 309 & 491 \\
\hline 3 & 800 & 85 & 65 & 75 & 725 \\
\hline
\end{tabular}

The sample was received dry and cut to length but was rough and contained regions of missing sample on the radial edge. The regions of missing sample along the perimeter were filled with Blu-Tac to prevent by-pass channels between sample and sleeve. The sample length is $79.3 \mathrm{~mm}$ and average diameter is $61.0 \mathrm{~mm}$. Rubber sheeting was wrapped around the sample to both protect it from further damage and to increase the diameter to fit the $80 \mathrm{~mm}$ diameter core holder. Rubber was used as the wrapping material as it is flexible but not compressible, allowing for transmission of confining pressure. The sample was saturated in a vacuum chamber with a solution analogous to brines sampled from Gloucester basin (Nghiem, 2015) that was prepared with 2364 ppm sodium bicarbonate and 102 ppm sodium chloride dissolved in de-ionized water. The unsteady-state technique was used to determine relative permeability at three effective stress states, which are provided in Table 1. These states represent confining and pore pressures commonly found in Australian coal seams during gas production. The effective stress of the sample was defined as being the confining pressure minus the average pore pressure. Confining pressure was held constant at 800 psi while the pore pressure was controlled by a twophase back pressure regulator at the outlet. Drainage unsteady-state testing was conducted with brine displaced by helium held at constant injection pressure using a Vindum Pulse-Free pump. The Paired-Pressure-Delivery mode allowed for maintaining constant pressure while measuring total injection volume. The brine production was monitored with a laboratory balance with $0.1 \mathrm{mg}$ accuracy. Gas injection and brine production volumes were both normalized to pore volumes by dividing by the total pore volume of the sample. During core flooding, we measured pore volumes of gas injected, volumes of brine produced and pressure drop across the sample. These measurements were then used for history matching. To correct relative permeability curves for capillary-end effect the experimental results were history matched using the reservoir simulator ECLIPSE100. The model was constructed using the single porosity and permeability dry gas option since no sorption effects were present with helium gas and it was assumed that flow occurs in the cleat system and not the matrix. A 1000 block section was used to simulate the core with 1 block on either end to simulate the inlet and outlet flow lines. To capture inlet and outlet discontinuities, the end blocks had $100 \%$ porosity, $13000 \mathrm{mD}$ permeability, unary function relative permeability curves and capillary pressure of zero for all saturations. The inlet and outlet were treated as constant pressure boundaries with a single injection well at the inlet block and a single production well at the outlet block. The wells were controlled through constant bottomhole pressure to mimic test conditions. Based on the experimental data; porosity, absolute permeability, relative permeability and capillary pressure curves were defined for each grid block. Porosity was calculated by taking the difference in wet to dry weights of the wrapped sample and dividing by the specific gravity of the brine solution. The absolute permeability to water was measured experimentally at the start of each unsteady-state core flood for each effective stress condition. Attempts to fit the data to the original Brooks-Corey correlation (Brooks and Corey, 1964) were unsuccessful (data not shown) so the modified Brooks-Corey correlation was used. Equations 1 (Lake, 1989) were used to generate the relative permeability curves shown. For the first simulation, production data did not match the simulated production data. Therefore, we adjusted the exponents (nw and ng) and irreducible water saturation (Swi), while gas endpoint relative permeability was held constant at the experimental value, until the simulated production data matched with experimental data.

$$
K_{r w}=K_{r w, \max }\left(\frac{S_{w}-S_{w i}}{1-S_{w i}-S_{g i}}\right)^{n_{w}}
$$




$$
K_{r g}=K_{r g, \max }\left(\frac{S_{g}-S_{g i}}{1-S_{w i}-S_{g i}}\right)^{n_{g}}
$$

Equations 1 shows modified Brooks-Corey where $\mathrm{Krw}$,max and $\mathrm{Krg}$,max are the measured maximum water and gas relative permeabilities; $\mathrm{Sgi}$ is the irreducible gas saturation which is assumed 0 for drainage; and nw and ng are the fitting exponents. Due to cleat deformation with changing effective stress, each effective stress state simulated required its own capillary pressure-saturation $(\mathrm{Pc}-\mathrm{Sw})$ curve. The capillary pressure-saturation curve was measured using a pressure chamber and porous membrane technique with helium displacing brine. The test was conducted at zero effective stress. This did not represent the unsteady-state testing conditions, to generate the required curves the Leverett J-function (Leverett, 1941) was used to approximate Pc-Sw curves for all three effective stress conditions. The capillary pressure data calculated from the J-function was then incorporated into the van Genuchten correlation (van Genuchten, 1980) to interpolate the missing data between experimental data points. With this approach Pc-Sw curves for each effective stress state were obtained by re-scaling the data based on the samples measured absolute permeability at a given effective stress. To substantiate this approach, the generated $\mathrm{Pc}-\mathrm{Sw}$ curves were compared to the unsteady-state end-point saturation and pressure data. The experimental capillary pressure for each core flood was taken as the maximum capillary pressure in the system, which was defined as the inlet pressure minus the outlet pressure (Lenormand and Lenormand, 2016). The irreducible water saturations for the respective core floods were taken from the history matched Corey curves. These capillary pressure-saturation points were then compared to the rescaled Pc-Sw curves to substantiate our approach. Furthermore, to improve our understanding of the cleat structure the sample was imaged using $\mathrm{X}$-ray micro-computed tomography (micro-CT), taken using a helical scanner at the Tyree X-Ray Laboratory at the School of Petroleum Engineering, UNSW. Images were collected at ambient conditions at a resolution of $27.58 \mu \mathrm{m}$ after the sample had been cleaned and dried. Dry scanning creates images with fractures clearly defined as dark lines, providing an understanding of the extent of the cleat network and cleat width distributions.

\section{Experimental Results}

The absolute permeability to water was measured at the start of each unsteady-state core flood. We found that absolute permeability decreased with increased effective stress. This trend has already been identified in coals and occurs due to the narrowing of the flow paths in the coal as cleats are compressed ( $\mathrm{Lu}$ et al, 2018). For this sample, the permeability decrease followed a power law function as seen in Figure 3.d. The power law function was used to predict absolute permeability at ambient conditions, which was used in the J-function correlation. As displayed in Figure 2, experimental results for the unsteady-state testing are expressed as pore volumes of brine produced versus pore volumes of gas injected. The history matches obtained, compared with the test data, were considered reasonable based on a sum of the square differences error analysis. With pore volumes of brine produced taken as the variable, no test had an error sum greater than 0.005 pore volumes of brine produced. It can be observed that the measured error is likely from the brine production curves before breakthrough, which is known to occur when the $\mathrm{Pc}-\mathrm{Sw}$ data at high saturation is not exact. This could be explained by the limited sensitivity of our pressure regulator $(1.0 \mathrm{psi})$ used for the porous plate experiment or that the Leverett-J function is not applicable for coal. Nevertheless, the error is less than 0.005 pore volumes of brine produced. Also, the expected capillary-end effect was also successfully simulated and used to demonstrate its impact on core saturation. An example of the simulated saturation profile from the $725 \mathrm{psi}$ effective stress state is shown in Figure 2.d. This profile indicates that close to $20-30 \%$ of the sample was affected by end effect, although it is unknown if this is typical for coal since no data on saturation profiles are available in the literature. 


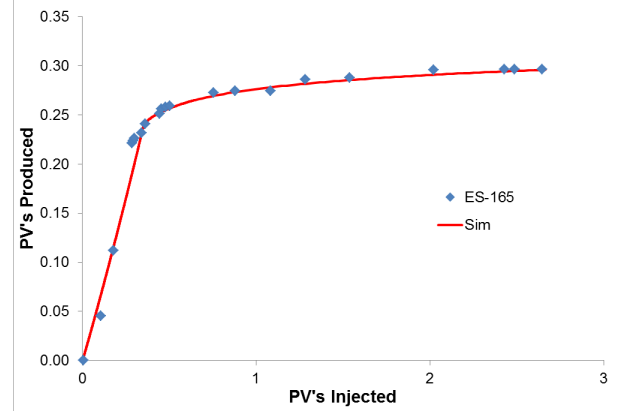

(a)

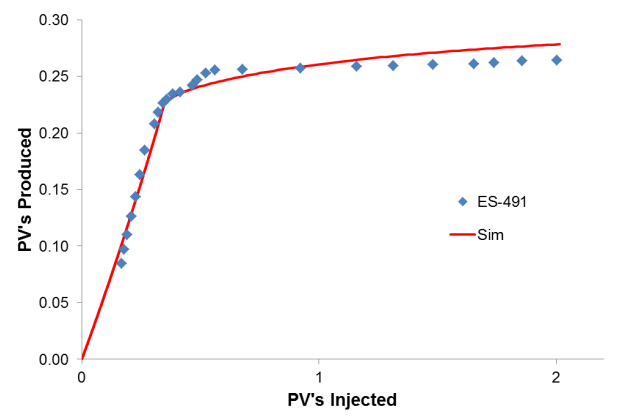

(b)

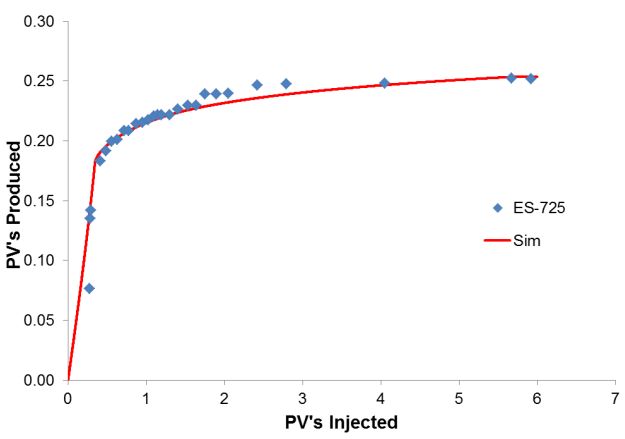

(c)

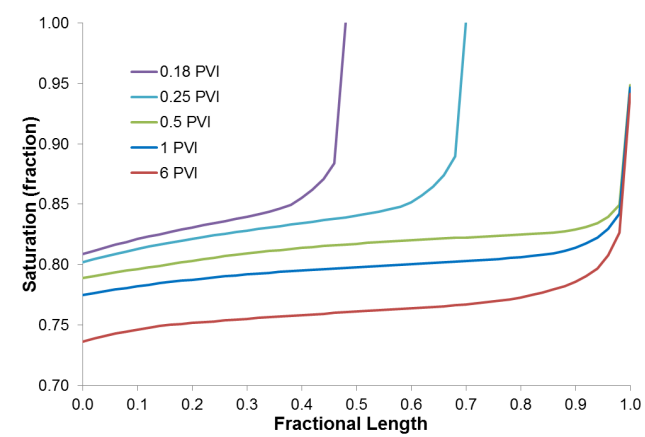

(d)

Figure 2. Demonstration of the pore volumes gas injected vs. pore volumes brine produced simulation matched to experimental data. 165, 491 and 725 psi effective stress for items (a), (b) and (c) respectively. (d) An example of simulated water saturation vs length at several pore volumes gas injected taken from the $725 \mathrm{psi}$ simulation.
The corrected relative permeability curves can be seen in Figure 3 along with the raw experimental data. We observe a shift to the left in the relative permeability once the end effect had been removed. It can be seen that both irreducible water saturation and gas end-point relative permeability both increased with increased effective stress, which matches trends observed by Reznik et al (1974) and Zhang et al (2017). The cross-points of the relative permeability curves also displayed an increase in saturation, shifting to the right as effective stress increased. The three irreducible water saturations obtained can be seen in Figure 5.a with the highest and lowest effective stress saturation values varying by 6 saturation units. Gas end-point relative permeability shows a significant change increasing from 0.11 to 0.38 , providing a clear trend when related to effective stress. These results combined are indicative of a reduction in cleat width as effective stress increases and increased gas phase permeability at high effective stress. Results from the capillary pressure testing in Figure 4.a indicate that, for zero effective stress, almost $38 \%$ of the water saturation was drained at a capillary pressure of 4.1 psi. This would indicate that $38 \%$ of the water was held in cleats greater than $5.09 \mu \mathrm{m}$ when using the Young-Laplace equation and assuming interfacial tension of $0.072 \mathrm{~N} / \mathrm{m}$ with zero contact angle for helium and brine. When the Leverett $\mathrm{J}$-function is applied to generate the curves at increased effective stress conditions the curves shift upward, indicating a reduction in average cleat width as the capillary pressure required to achieve equal saturations increases. Figure 4.c shows the predicted Pc-Sw curves with the corresponding test end points overlaid. The cleat widths predicted by the J-function can also be compared to the experimental data points obtained from the unsteady-state core flood.

The minimum cleat width drained from the 164 psi test end-point was calculated to be $2.09 \mu \mathrm{m}$, deviating from the predicted value by $9 \%$. At 491 psi effective stress, the minimum cleat width was $1.74 \mu \mathrm{m}$ with a deviation of $1 \%$. The 725 psi test showed the largest deviation at $62 \%$ with the measured minimum cleat width drained calculated as $1.13 \mu \mathrm{m}$. These deviations could be due to the poroelasticity of coal since the 
Leverett function was developed for conventional reservoir rocks, however, further investigations are required.

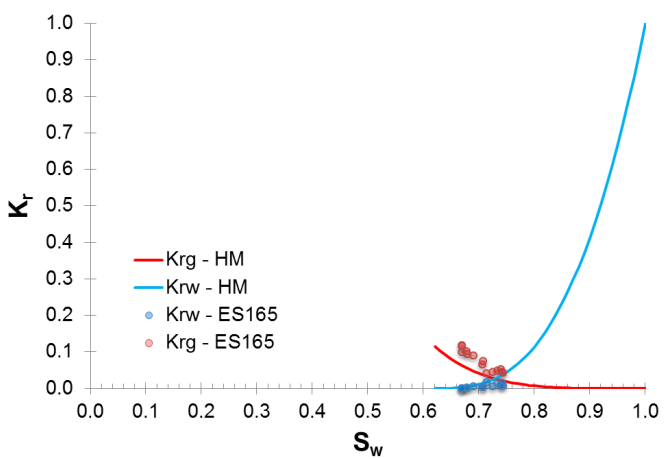

(a)

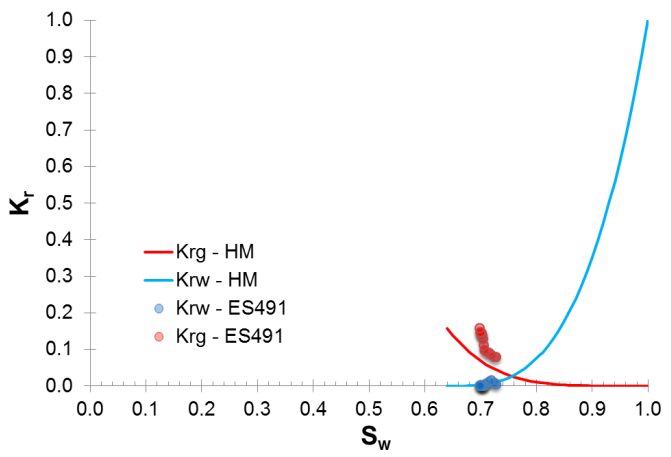

(b)

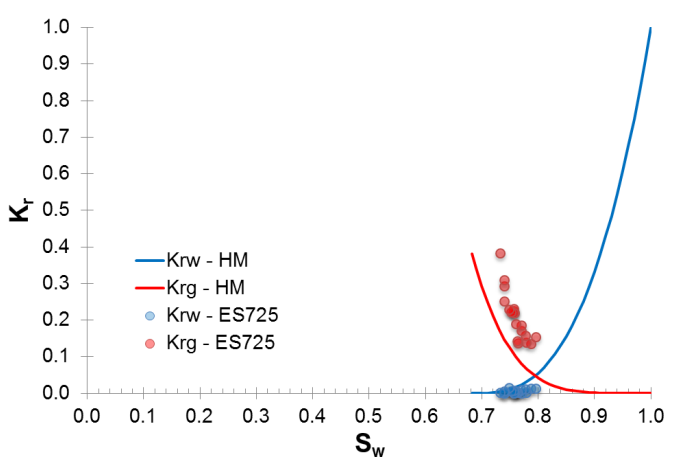

(c)

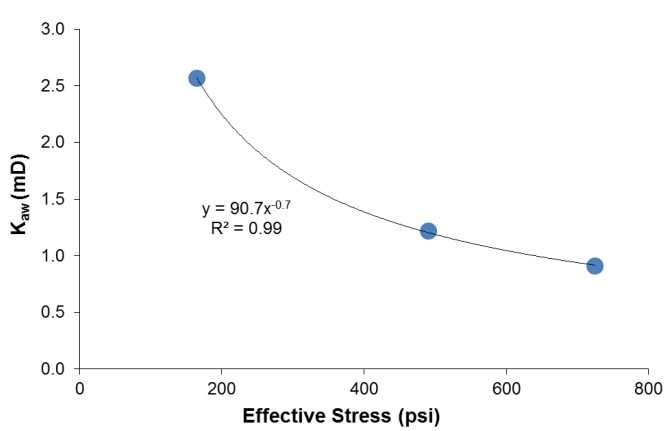

(d)
Figure 3. Relative permeability curves derived from history matching compared to raw data for the three effective stress states $165 \mathrm{psi}$ (a), 491 psi (b) and 725 psi (c); (d) Absolute water permeability vs effective stress.

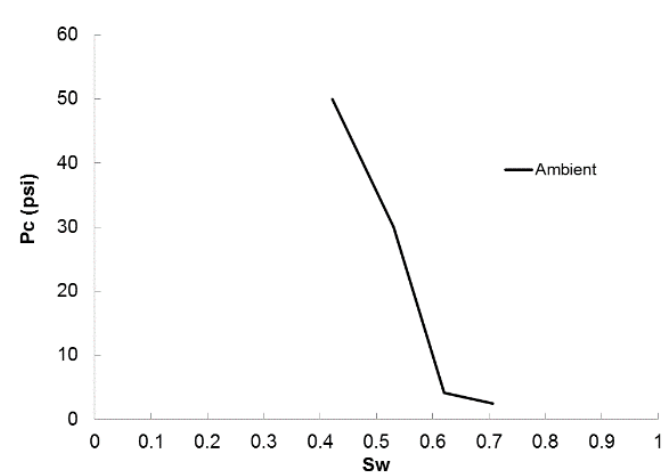

(a)

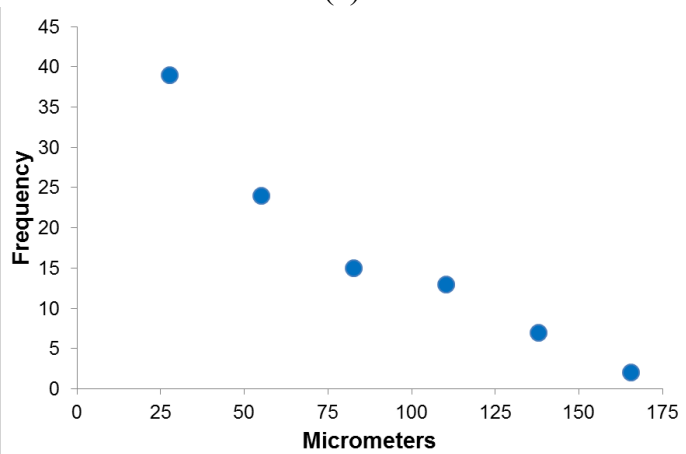

(b)

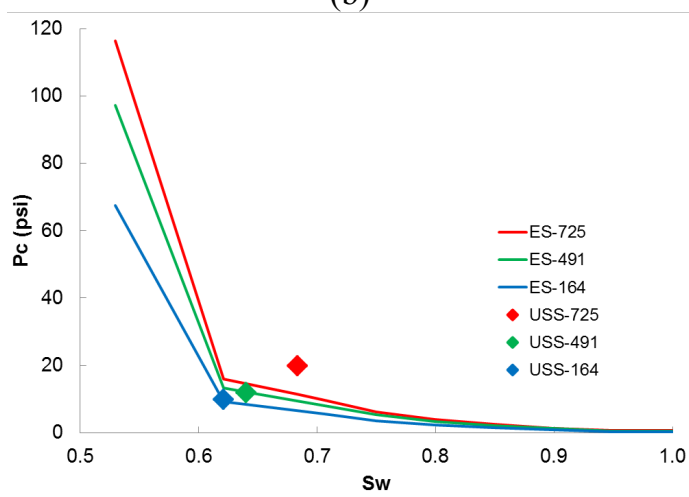

(c)

Figure 4: (a) Capillary pressure test data from porous plate at ambient conditions. (b) Cleat width distribution of a random 100 cleats taken from a single micro-CT image. (c) Comparison of effective stress curves used for history matching and corrected unsteady-state core flood end point saturations.

The micro-CT image of coal (Figure 1.b) displayed a well-developed cleat network spanning the length of the sample. A random sampling of 100 cleats, with the minimum 
observed being a single voxel $(27.58 \mu \mathrm{m})$ and the largest observed being 6 voxels $(165.48 \mu \mathrm{m})$, was taken from a single image, the distribution is reported in Figure 4.b. The shortest and longest cleat widths correspond to a capillary pressure of 0.76 and $0.13 \mathrm{psi}$, respectively. This is well below the maximum capillary pressures applied to the sample during the unsteady-state core floods, however it is unknown how much these widths reduce once confining pressure is applied to the sample since the image was collected at ambient conditions. One recent study shows that the reduction in cleat width can be significant (Lu et al, 2018).

\section{Discussion}

In Figure 5, we cross-plot the main relative permeability characteristics versus effective stress. The strongest trend was apparent for gas end-point relative permeability with the highest effective stress test value corresponding to a $3.15 \mathrm{x}$ increase in relative permeability. Irreducible water saturation and cross-point also appeared to increase with increasing effective stress, however, the trend is weak relative to gas end-point relative permeability versus effective stress.

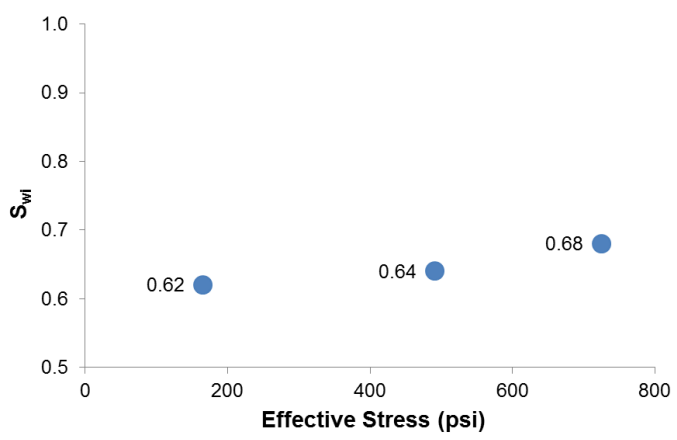

(a)

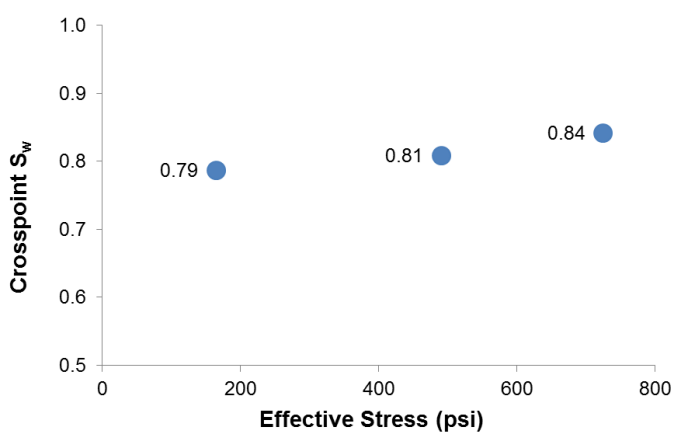

(b)

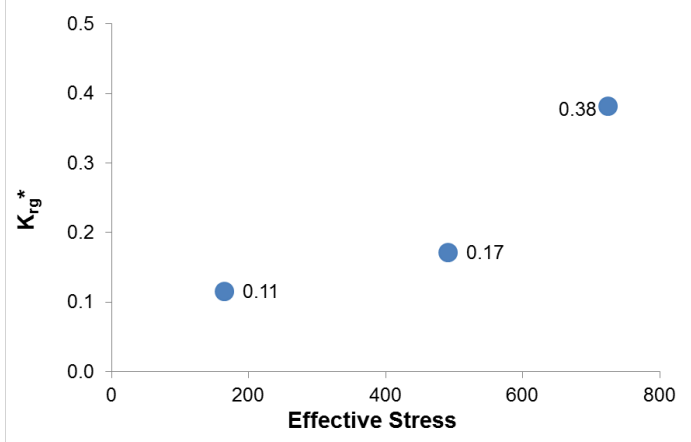

(c)

Figure 5. Influence of effective stress on irreducible water saturation (a), relative permeability cross-point (b) and gas relative permeability end-point (c).

Gas end-point relative permeability exhibited a significant increase as effective stress was increased (Figure 5.c). Considering that low pore pressure occurred at high effective stress the observed increase could be attributed to gas slippage. In addition, reduction in cleat width distribution would also increase the slippage effect as more cleat lengths are reduced below the mean free path of helium. Recent experimental works have shown that gas slippage in coal increases with increasing effective stress (Niu et al. 2018) causing permeability to increase. Herein, gas effective permeability was normalized by water phase absolute permeability measured before the start of the unsteady-state test. Therefore, increased gas relative permeability could be attributed to the increased gas slippage. It is also interesting to note that even though irreducible water saturation increases with increasing effective stress, gas relative permeability end-point does not decrease. Irreducible water saturation increased with effective stress (Figure 5.a) indicating a change in cleat width distribution as less water can be mobilized for the given capillary pressure. This was in agreement with our understanding that coal cleats are compressible ( $\mathrm{Lu}$ et al, 2018). It is also in agreement with the Leverett $\mathrm{J}$-function analysis previously shown. However, the Leverett model does not account for matrix deformation and is based on an idealized granular porous material possibly resulting in the variation between the predicted and experimental measured capillary 
pressure-saturation values. The cross-point saturation also increased with increasing effective stress (Figure 5.b). In conventional reservoirs this can indicate a change in wettability or sample heterogeneity. A rock becoming more hydrophilic will exhibit a shift to the right in cross points, while heterogeneity can lead to early breakthrough during testing resulting in atypical cross-points. In these tests a non-polar gas molecule was used and so this change is most likely due to the change in cleat topology and/or gas slippage. However, changes in coal wettability could be another contributing factor that we have yet to investigate, which should be investigated when using methane gas.

\section{Conclusion}

The unsteady-state method was used to measure coal relative permeability at three different effective stress states. The testing was conducted with a non-sorbing gas and is a simplified experimental condition to understand how mechanical deformation of coal influences its relative permeability. To test under production conditions with methane gas the mechanism of gas desorption and diffusion into the cleats would have to be mimicked and precisely controlled. Therefore, we used helium gas to decouple these mechanisms from our analysis. No standard method currently exists to undertake coal testing with methane under reservoir conditions but we plan to investigate possible techniques. History matching was shown to correct for capillary-end effect, as evidenced by the shift of the curves to the left when compared to the measured data. Analysis of the corrected curves allowed us to observe trends in key points along the relative permeability curves. As effective stress was increased, we observed gas end-point relative permeability increased, irreducible water saturation increased and the relative permeability cross-point shift to the right. These trends indicate a clear link between effective stress and relative permeability indicating a connection between physical process in coal and relative permeability behaviour. This behaviour was not described mathematically but we plan to investigate the observed physics in future work. Even so, without a fully developed coal relative permeability model, we demonstrated that for the tested sample the modified Brooks-Corey correlation was a sufficient relative permeability model. From our results, we find that the modified Brooks-Corey correlation is suitable for coal relative permeability. There is still a significant amount of research required to fully understand the transport of methane gas and water through coal. We recommend focus should be directed towards:

- A valid method for testing with methane to compare results and establish effective stress states.

- Development of an improved core encasement and preservation technique.

- A capillary pressure testing method that incorporates effective stress.

- A robust capillary pressure model is required that can accurately model capillary pressure change with effective stress.

- $\quad$ The link between effective stress, cleat width and relative permeability points of interest should be described mathematically and linked to physical parameters.

We would like to thank Tyree X-Ray Laboratory at the School of Petroleum Engineering, UNSW for their assistance in imaging and image processing. We also acknowledge funding from the Australian Research Council Discovery Grant DP170104417.

\section{References}

1. X. Lu, R.T. Armstrong, and P. Mostaghimi (2018), "High-pressure X-ray imaging to interpret coal permeability", Fuel, vol. 226, pp. 573-582

2. Y. Niu, P. Mostaghimi, I. Shikhov, Z. Chen, and R.T. Armstrong (2018), "Coal permeability: Gas slippage linked to permeability rebound", Fuel, vol. 215, pp. 844-852.

3. S. Wu, D. Tang, S. Li, Y. Meng, and W. Lin (2017), "Evaluation of pore development in different coal reservoirs based on centrifugation experiment", Journal of Petroleum Science and Engineering, Vol. 157, pp. 1095-1105.

4. X. Zhang, C. Wu, and S. Liu (2017), "Characteristic analysis and fractal model of 
the gas-water relative permeability of coal under different confining pressures", Journal of Petroleum Science and Engineering, Vol. 159, pp. 488-496.

5. Y. Liang, J. Sheng, and J. Hildebrand (2017), "Dynamic Permeability Models in Dual-Porosity System for Unconventional Reservoirs: Case Studies and Sensitivity Analysis", SPE Reservoir Characterisation and Simulation Conference and Exhibition, 8-10 May, Abu Dhabi, UAE, SPE-186072MS.

6. I. Siregar, Y. Niu, P. Mostaghimi, and R.T. Armstrong (2017), "Coal ash content estimation using fuzzy curves and ensemble neural networks for well log analysis", International Journal of Coal Geology, vol. 181(no. 1), pp. 11-22.

7. R. Lenormand, and G. Lenormand (2016), "RECOMMENDED PROCEDURE FOR DETERMINATION OF RELATIVE PERMEABILITIES", Presented at the International Symposium of the Society of Core Analysts held in Snowmass, Colorado, USA, 21-26 August 2016(SCA-2016-004).

8. P. Mostaghimi, et al. (2016), "Pose Scale Characterisaztion of Coal: An Unconventional Challenge", Society of Petroleum Engineers, Abu Dhabi International Petroleum Exhibition \& Conference, 7-10 November, Abu Dhabi, UAE, Conference Paper SPE-183411-MS.

9. L.D. Nghiem, C. Elters, A. Simon, T. Tatsuya, and W. Price (2015), "Coal seam gas produced water treatment by ultrafiltration, reverse osmosis and multieffect distillation: A pilot study", Separation and Purification Technology, vol. 146, pp. 94-100.

10. S.A. Mahoney, T.E. Rufford, A.S.K. Dmyterko, V. Rudolph, and K.M. Steel (2015), "The Effect of Rank and Lithotype on Coal Wettability and its Application to Coal Relative Permeability Models", Society of Petroleum Engineers, SPE Asia Pacific Unconventional Resources Conference and Exhibition held in Brisbane, Australia, 9-11 November 2015, (SPE-176870-MS).

11. J. Zhang, Q. Feng, X. Zhang, S. Wen, and Y. Zhai (2015), "Relative Permeability of Coal: A Review”, Transport in Porous Media, Vol. 106, pp. 563-594.

12. X. Guo, Y. Yao, and D. Liu (2014), "Characteristics of Coal Matrix Compressibility: An Investigation by Mercury Intrusion Porosimetry", Energy Fuels, vol. 28(no. 6), pp. 3673-3678.

13. D. Chen, Z. Pan, J. Liu, and L.D. Connell (2013), “An Improved Relative Permeability
Model for Coal Reservoirs", International Journal of Coal Geology Vol. 109-110 (2013) pp. 45-57.

14. J.Q. Shi, and S. Durucan (2004), "Drawdown Induced Changes in Permeability of Coalbeds: A New Interpretation of the Reservoir Response to Primary Recovery", Transport in Porous Media, Vol. 56(No. 01), pp. 1-16.

15. L.W. Gurba, and C.R. Weber (2000), "Coal Petrology and Coalbed Methane Occurrence in the Gloucester Basin, NSW, Australia”, The Society for Organic Petrology, 17th Annual Meeting Abstracts and Program.

16. J.P. Seidle, M.W. Jeansonne, and D.J. Erickson (1992), “Application of Matchstick Geometry To Stress Dependent Permeability in Coals", Society of Petroleum Engineers, SPE Rocky Mountain Regional Meeting, 18-21 May, Casper, Wyoming, Conference Paper SPE-24361-MS.

17. J.C. Close, and M.J. Mavor (1991), "Influence of Coal Composition and Rank on Fracture Development in Fruitland Coal Gas Reservoirs of San Juan Basin, Rocky Mountain Association of Geologists", Coalbed Methane of Western North America

18. S. Harpalani, and R.A. Schraufnagel (1990), "Shrinkage of Coal Matrix with Release of Gas and its Impact on Permeability of Coal",Fuel,Vol.69,pp.551 - 556.

19. M.Th. van Genuchten (1980), "A Closedform Equation for Predicting Hydraulic Conductivity of Unsaturated Soils", Soil Science Society of America Journal, Vol. 44(No. 5).

20. A. A. Reznik, M. K. Dabbous, P. F. Fulton, and J. J. Taber (1974), “Air-Water Relative Permeability Studies of Pittsburgh and Pocahontas Coals", Society of Petroleum Engineers, vol. 14(no. 06), pp. 556 - 562 (SPE-4711-B).

21. R.H. Brooks, and A.T. Corey (1964), "Hydraulic Properties of Porous Media, Colorado State University", Hydrology Papers, Paper No. 3.

22. M. C. Leverett, (1941), "Capillary Behavior in Porous Solids", Society of Petroleum Engineers, Vol. 142, No. 01, (SPE-941152G). 